\title{
ENDOWMENT FUND
}

In 1923 an Endowment Fund was collected to meet the greater demands on the Society's publication program caused by the ever increasing number of important mathematical memoirs. Of this fund, which amounted to some $\$ 94,000$ in 1960 , a considerable proportion was contributed by members of the Society. In 1961 upon the death of the last legatees under the will of the late Robert Henderson, for many years a Trustee of the Society, the Society received the entire principal of the estate for its Endowment Fund which now amounts to some $\$ 647,000$.

\section{SPECIAL FUNDS}

\section{$(\$ 500$ or more)}

\section{The Bôcher Memorial Prize}

This prize was founded in memory of Professor Maxime Bôcher. It is awarded every five years for a notable research memoir in analysis which has appeared during the preceding five years in a recognized journal published in the United States or Canada; the recipient must be a member of the Society, and not more than fifty years old at the time of publication of his memoir.

First (Preliminary) Award, 1923: To G. D. Birkhoff, for his memoir Dynamical systems with two degrees of freedom.

Second Award, 1924: To E. T. Bell, for his memoir Arithmetical paraphrases, and to Solomon Lefschetz, for his memoir On certain numerical invariants with applications to abelian varieties.

Third Award, 1928: To J. W. Alexander, for his memoir Combinatorial analysis situs.

Fourth Award, 1933: To Marston Morse, for his memoir The foundations of a theory of the calculus of variations in the large in m-space, and to Norbert Wiener, for his memoir Tauberian theorems.

Fifth Award, 1938: To John von Neumann, for his memoir Almost periodic functions and groups.

Sixth Award, 1943: To Jesse Douglas, for his memoirs Green's functions and the problem of Plateau, The most general form of the problem of Plateau, and Solution of the inverse problem of the calculus of variations.

Seventh Award, 1948: To A. C. Schaeffer and D. C. Spencer for their memoir Coefficients of schlicht functions.

Eighth Award, 1953: To Norman Levinson for his contributions to the theory of linear, nonlinear, ordinary, and partial differential equations contained in his papers of recent years. tions.

Ninth Award, 1959: To Louis Nirenberg for his work in partial differential equa- 


\section{The Frank Nelson Cole Prize in Algebra The Frank Nelson Cole Prize in the Theory of Numbers}

These prizes were founded in honor of Professor Frank Nelson Cole, on the occasion of his retirement as Secretary of the American Mathematical Society and Editor of the Bulletin, after twenty-five years of service; the fund was later doubled by his son, Charles A. Cole. They are awarded at five-year intervals for contributions to algebra and the theory of numbers, respectively, under restrictions similar to those for the Bôcher prize.

First Award, 1928: To L. E. Dickson, for his book Algebra und ihre Zahlentheorie, Zurich, 1927.

Second Award, 1931: H. S. Vandiver, for his several papers on Fermat's last theorem published in the Transactions of the American Mathematical Society and the Annals of Mathematics during the last five years, with special reference to a paper entitled On Fermat's last theorem, which appeared in volume 31 of the Transactions.

Third Award, 1939: To A. A. Albert, for his papers on the construction of Riemann matrices, published in volumes 35 and 36 of the Annals of Mathematics.

Fourth Award, 1941: To Claude Chevalley, for his paper entitled La theorie du corps de classes, published in volume 41 of the Annals of Mathematics.

Fifth Award, 1944: To Oscar Zariski, for four papers on algebraic varieties, published in volumes 61 and 62 of the American Journal of Mathematics and volumes 40 and 41 of the Annals of Mathematics.

Sixth Award, 1946: To H. B. Mann for his paper entitled $A$ proof of the fundamental theorem on the density of sums of sets of positive integers, published in volume 43 of the Annals of Mathematics.

Seventh Award, 1949: To Richard Brauer, for his memoir On Artin's L-series with general group characters, published in volume 48 of the Annals of Mathematics.

Eighth Award, 1951: To Paul Erdös, for his many papers in the Theory of Numbers, and in particular for his paper On a new method in elementary number theory which leads to an elementary proof of the prime number theorem, published in the Proceedings of the National Academy, volume 35, pp. 374-385, July, 1949.

Ninth Award, 1954: To Harish-Chandra, for his papers on representations of semisimple Lie algebras and groups, and particularly for his paper On some applications of the universal enveloping algebra of a semisimple Lie algebra, published in volume 70 of the Transactions of the American Mathematical Society.

Tenth Award, 1956: To John Tate, for his paper The higher dimensional cohomology groups of class field theory, published in the Annals of Mathematics, volume 56, pp. 294-297, 1952.

Eleventh Award, 1960: To Serge Lang, for his paper entitled Unramified class field theory over function fields in several variables, published in volume 64 of the Annals of Mathematics, and to Maxwell Rosenlicht for his papers Generalized Jacobian varieties and $A$ universal mapping property of generalized Jacobians, published in volumes $\mathbf{5 9}$ and 66 of the Annals of Mathematics. 
Twelfth Award, 1962: To Kenkichi Iwasawa, for his paper entitled Gamma extensions of number fields, published in volume 65 of the Bulletin of the American Mathematical Society, and to B. W. Dwork for his paper On the rationality of the zeta function, published in volume 82 of the American Journal of Mathematics.

\section{The Eliakim Hastings Moore Fund}

This fund was founded in 1922 in honor of Professor Eliakim Hastings Moore, on the occasion of the twenty-fifth anniversary meetings of the Chicago Section of the American Mathematical Society. The income from the fund of $\$ 2,575$ is to be used at the discretion of the Council of the Society, for the publication of important mathematical books or memoirs, or the award of prizes.

\section{The Marion Reilly Fund}

Dean Marion Reilly willed to the American Mathematical Society a portion of her estate to be used for the advancement of research in pure mathematics. The principal of this fund is $\$ 23,650$.

\section{The Ernest William Brown Fund}

From the estate of Professor Ernest William Brown, a fund of $\$ 1,000$ is available, the interest on which, at the discretion of the Council, can be used for the furtherance of such mathematical interests as (a) the publication of important mathematical books, memoirs, and periodicals, and (b) lectures to be delivered on special occasions by invited guests of the Society.

\section{The Robert Henderson Fund}

Upon his retirement from the Board of Trustees on December 31, 1940, Dr. Robert Henderson presented to the Society an unrestricted gift of $\$ 1,000$ which the Trustees have set aside as the Robert Henderson Fund.

\section{The James K. Whittemore Fund}

From the estate of Professor James K. Whittemore, a fund of $\$ 1,000$ is available for use in the interest of mathematical research.

\section{The Genevra B. Hutchinson Fund}

A fund of $\$ 1,000$ from the estate of the late Genevra B. Hutchinson, in memory of her husband Professor J. I. Hutchinson, for use, at the discretion of the Council and Trustees, in the advancement of mathematical research.

\section{The Helen A. Merrill Fund}

From the estate of the late Professor Helen A. Merrill, a fund of $\$ 650$ is available for use in the interest of mathematical research.

\section{The Solomon A. Joffe Fund}

An unrestricted gift of $\$ 3,000$ presented to the Society by Solomon A. Joffe, which the Trustees have set aside as the Solomon A. Joffe Fund.

\section{Library Proceeds Fund}

A fund of $\$ 66,000$ established by the Trustees in 1951 from the proceeds of the sale of the Society's Library.

\section{The Oswald Veblen Fund}

A fund of $\$ 1,000$ contributed by former students and colleagues in memory of Oswald Veblen and established by the Trustees in 1961 . 